\title{
SEISMIC REHABILITATION OF MASONRY HERITAGE STRUCTURES WITH BASE-ISOLATION AND WITH SELECTED CONTEMPORARY STRENGTHENING MEASURES
}

\author{
VOJKO KILAR \& SIMON PETROVČIČ \\ University of Ljubljana, Faculty of Architecture, Slovenia.
}

\begin{abstract}
In the seismically active zones of southern and central Europe, unreinforced masonry (URM) structures are one of the most common types of buildings. Some of them possess a high historical value and could therefore be classified as part of the architectural heritage, requiring special attention with regard to their preservation and retrofitting measures. In practice, however, the accurate prediction of the seismic response of such structures often proves to be difficult, not only due to the complex geometrical features of their individual architectural parts, but also due to the composite and non-homogeneous nature of URM. Due to the great variety of structural configurations and materials used, rational approaches for the assessment of the seismic safety levels of such buildings are needed. The paper analyses the applicability of two contemporary seismic strengthening measures, namely the use of fibre-reinforced polymer composites and the implementation of base-isolation to achieve the desired, code-based seismic protection levels. A three-storey masonry building was considered in the study. Non-linear static analyses for different levels of seismic intensities were conducted on a mathematical model of the fixed-base, FRP-strengthened and base-isolated variants of the structure.
\end{abstract}

Keywords: base isolation, fibre-reinforced polymers, historic masonry structures, seismic rehabilitation

\section{INTRODUCTION}

In general, architectural conservation guidelines (e.g. ICOMOS Charters) and guidelines for structural restoration (e.g. Eurocodes) usually lead to contradictory approaches to heritage conservation. On the one hand, architectural conservation guidelines follow the minimum intervention concept by which the applied interventions should be limited, reversible and should strive towards minizing the impact into the heritage substance. On the other hand, the aim of structural restoration measures is to maximise safety and resilience of the structure by using strengthening techniques which are often very invasive and irreversible.

In this paper, two contemporary seismic strengthening measures with varying degrees of invasiveness and strengthening efficiency are presented and employed in a case study numerical simulation on a typical neo-renaissance masonry heritage building. Firstly, the initial building is strengthened with fibre-reinforced polymer (FRP) composites. Compared to traditional techniques, FRP composites are lightweight, noncorrosive and exhibit high tensile strength and stiffness [1]. FRP materials usually are applied in different geometric layouts on masonry panels. In the context of architectural conservation, this strengthening method is moderately invasive.

Secondly, seismic base isolation is implemented in the initial structure. A base isolation system consists of a decoupling isolation layer between the building and the ground. The isolation layer is made of devices that support the building against static actions and, in case of seismic actions, implement a decoupling effect of the dynamic response of the building compared to the ground. A base-isolated building is characterised by a smaller acceleration response, leading to a smaller amount of forces of inertia, a smaller amount of interstorey drifts 
and internal forces in structural elements [2]. The implementation of base isolation in existing buildings is usually less invasive then FRP strengthening, since all major interventions are concentrated on the base storey, where isolation devices are usually installed. The installation of base isolation is therefore very limited: installation issues and accessibility to the equipment for inspection, maintenance, or replacement purposes are the most challenging factors to be met in the implementation of the base-isolation of existing buildings. The results for BI variant of the building are taken from our previous papers and are not presented here in detail.

The paper aims to compare the two strengthening techniques in terms of the achieved level seismic resistance. In the final part of the paper, comparison of results based on static pushover analyses for various ranges of seismic intensity are presented and discussed. Each selected strengthening measure is assessed in terms of its strengthening efficiency.

What is more, the authors of the paper have in their previous research [3] proposed a refined technique for the modelling and analysis of regular unreinforced masonry (URM) structures, which is based on the equivalent frame approach, and incorporates linear beam elements and the plastic hinge concept. Therefore, this study also aims in applying this technique also to URM structures that have been strengthened with FRP composites. An application of the technique to base-isolated structures has already been successfully undertaken [4].

\section{ANALYSED MASONRY BUILDING}

\subsection{Building characteristics}

In the conducted case study, a base-isolated masonry building typical for the neo-renaissance era in Europe was analysed. The building is a three-storey URM structure with floor plan dimensions $24.6 \mathrm{~m} \times 12.9 \mathrm{~m}$ (directions $\mathrm{X}$ and $\mathrm{Y}$, respectively) and a total height of $15.8 \mathrm{~m}$. The examined masonry building is schematically presented in Fig. 1.

Detailed information regarding its geometry, mechanical parameters of masonry and modelling are presented in a previous paper by the authors]. The structure can be divided into four different types of planar wall assemblies, i.e. Wx-1, Wx-2, Wy-1 and Wy-2. Each planar wall of the structure has been modelled based on the equivalent frame approach, using piers, spandrels and rigid zones as indicated in Fig. 1. The storey masses amount to $\mathrm{m}_{\text {base }}=878$ tons, $\mathrm{m}_{1}=748$ tons and $\mathrm{m}_{2}=499$ tons, whereas the fundamental periods of the structure are $\mathrm{T}_{\mathrm{X}}=0.39 \mathrm{~s}$ (in the $\mathrm{X}$-direction) and $\mathrm{T}_{\mathrm{Y}}=0.29 \mathrm{~s}$ (in the Y-direction).

The building is located in a moderately active seismic area, with a design ground acceleration equal to $\mathrm{a}_{\mathrm{g}}=0.25 \mathrm{~g}$ and a soft soil site that corresponds to sub-soil of class $\mathrm{C}$ in accordance with Eurocode 8-1. Through a preliminary pushover analysis of the fixed-base structure, it has been determined that the behaviour factor of the building equals to $q=2.5$ for the X-direction of seismic loading and $\mathrm{q}=2.2$ for the Y-direction [3].

\subsection{Equivalent frame modelling}

In general, masonry walls often incorporate irregularities in the form of an irregular layout of openings, so that special modelling considerations have to be taken into account [5]. In the cases of irregular geometry, a macro-element discretisation of masonry elements is usually adopted, which is able to predict the seismic response with sufficient accuracy and with relatively low computational costs compared to those involved in the case of conventional nonlinear finite element modelling approaches [6]. 

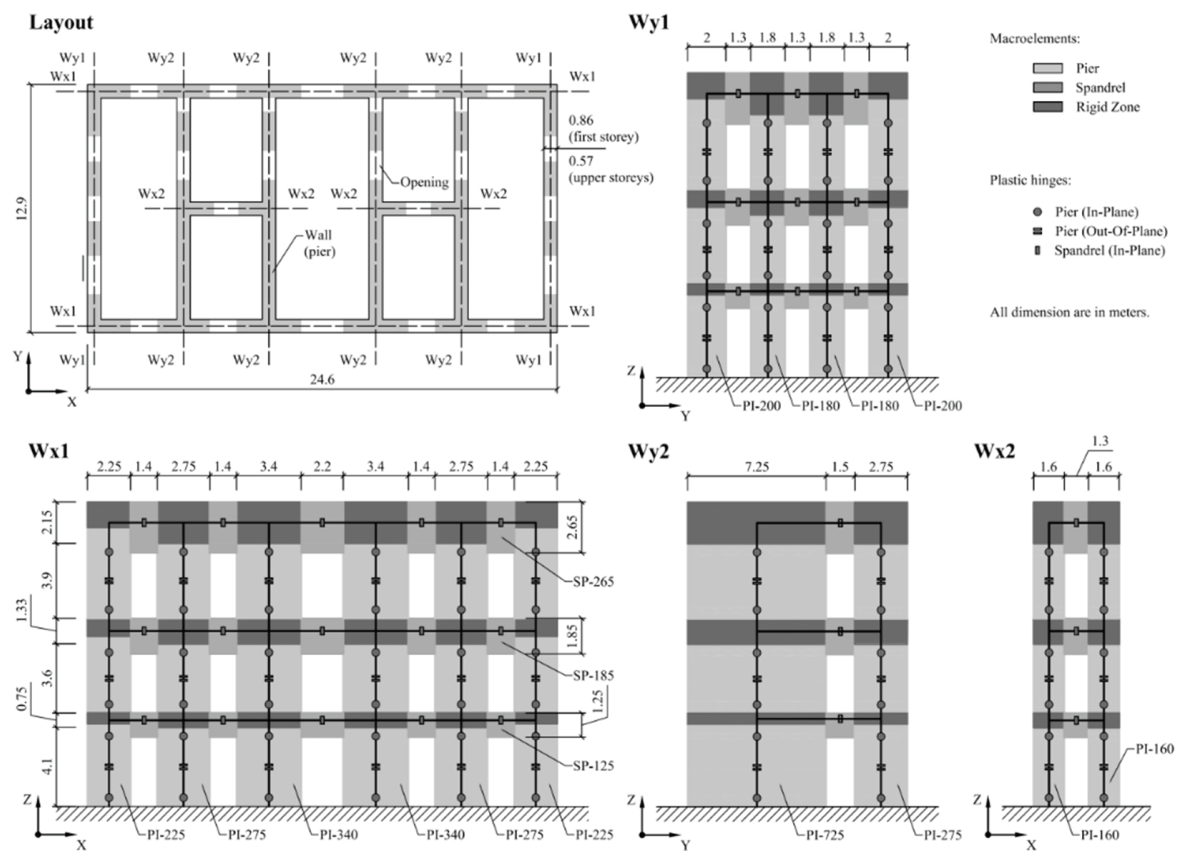

Figure 1: Examined masonry building. (Source: Petrovčič \& Kilar, 2013.)

The in-plane lateral resistance of URM buildings is provided by the piers and spandrels. In addition to the vertical force in the piers due to the dead loads, these resisting elements are under horizontal seismic actions at the base of the structure subjected to shear and bending [7]. Depending on the width to height ratio of a masonry element and on the respective values of the normal force, bending moment and shear force, three failure mechanisms might be observed (Table 1).

The symbol $\theta_{c r}$ in Table 1 denotes the pier's chord rotation at the formation of the first crack (elastic limit). In the case of the analysed building values of $\theta_{c r}$ lie between 0.003 and 0.01 . The symbol $\alpha_{V}$ is the pier's shear ratio, considering the zero moment contra-flexure point and the height-to-width ratio of the pier (for details see [3]). The ratio $l_{s p} / h_{s p}$ is to lengthto-height ratio of the spandrel.

The equivalent frame discretisation of URM and seismic failure modes are schematically presented in Fig. 2. In order to accommodate different failure modes in as simple as possible and simultaneously computationally effective way, the authors proposed a new technique for the modelling and analysis of regular URM structures [3]. This technique is based on the

Table 1: Seismic failure modes of URM.

\begin{tabular}{lllllll}
\hline & \multicolumn{3}{c}{ Limit rotations for piers } & \multicolumn{2}{c}{ Limit rotations for spandrels } \\
\cline { 2 - 7 } Failure mode & $\theta_{D L}$ & $\theta_{S D}$ & $\theta_{N C}$ & $\theta_{D L}$ & $\theta_{S D}$ & $\theta_{N C}$ \\
\hline Rocking & $\theta_{c r}$ & $0.008 \alpha_{V}$ & $0.011 \alpha_{V}$ & 0.002 & $0.008 l_{s p} h \mathrm{sp}$ & 0.015 \\
Diagonal cracking & $\theta_{c r}$ & 0.004 & 0.005 & 0.001 & 0.004 & 0.020 \\
Shear sliding & $\theta_{c r}$ & 0.004 & 0.005 & & & \\
\hline
\end{tabular}



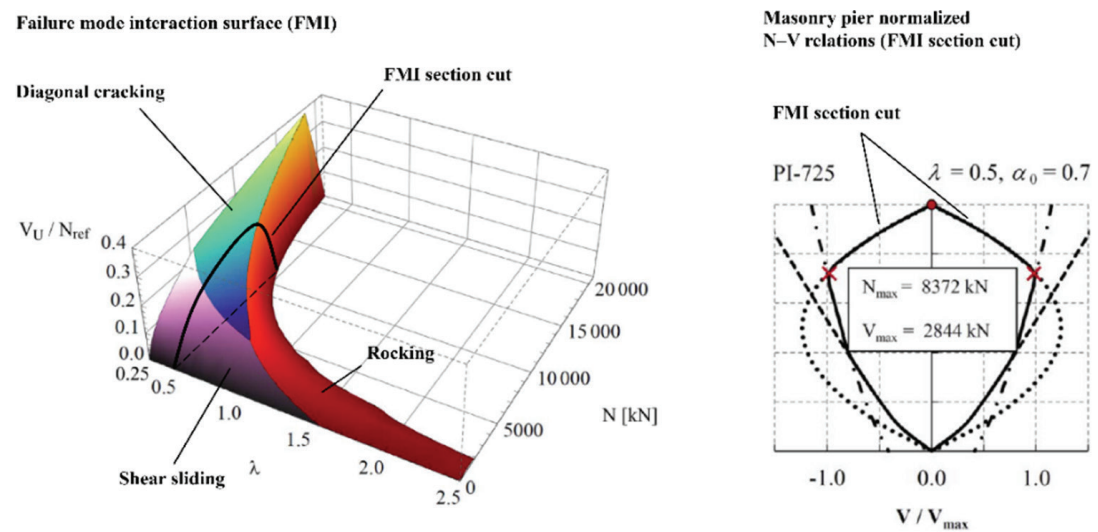

Figure 2: An example of a failure mode interaction surface of a masonry pier (left) and normalised pier $\mathrm{N}-\mathrm{V}$ relations (right).

equivalent frame approach and incorporates linear beam elements and the plastic hinge concept. The complex seismic failure mechanism of masonry piers is expressed by a single failure mode interaction surface (an 'FMI surface'), taking into account the influence of variation in the pier's vertical loading, and its bending moment distribution. The ultimate lateral strength of a masonry element is expressed as a section which cuts through the FMI surface. A single failure mode interaction plastic hinge (an 'FMI hinge') for each masonry frame element is introduced by combining the specific failure modes, taking into account their minimum envelope. In the present paper, a nonlinear equivalent frame 3D mathematical model of the initial (fixed-base) structure was created in the structural analysis program SAP2000 [6] based on this technique. The model was extended to include the FRP-strengthened variant and the base-isolated variant of the building.

\section{SEISMIC STRENGTHENING}

\subsection{Fiber- reinforced polymers}

The primary objective of FRP strengthening is to increase the capacity of each member as well as the overall capacity of the masonry structure. For the design of the FRP strengthening of URM piers, the guidelines CNR-DT 200/2004 [9] were considered.

The shear capacity of masonry pier strengthened with FRP applied on both sides of the panel can be seen as the combination of two resisting mechanisms [9]: (i) shear forces due to friction in presence of compression loads and (ii) for elements capable of resisting tensile stress a truss mechanism becomes active, and shear forces are carried out by equilibrium.

The CNR-DT 200/2004 defines the design shear capacity, $V_{R d}$, of the FRP strengthened masonry panel in the following manner:

$$
V_{R d}=\min \left(V_{R d}+V_{R d, f}, V_{R d, \text { max }}\right)
$$

In the above expression, the $\mathrm{V}_{\mathrm{Rd}, \mathrm{m}}$ denotes the masonry contribution to the shear strength of the panel, defined as:

$$
V_{R d, m}=\frac{1}{\gamma_{R d}} \cdot f_{v d} \cdot d \cdot t
$$


while the $\mathrm{V}_{\mathrm{Rd}, \mathrm{f}}$ denotes the FRP contribution, which may be evaluated as follows:

$$
V_{R d, f}=\frac{1}{\gamma_{R d}} \cdot 0.6 \cdot \frac{A_{f w}}{p_{f}} \cdot f_{f d} \cdot d
$$

The symbols in eqns (13) have the following definitions: $\mathrm{g}_{\mathrm{Rd}}$ is the partial factor to be assumed equal to $1.20, d$ is the distance between the compression side of the masonry and the centroid of FRP flexural strengthening, $\mathrm{t}$ is the masonry panel thickness, $\mathrm{f}_{\mathrm{vd}}$ is the design shear strength of the masonry, equal to $f_{v k} / \gamma_{M}, A_{f w}$ is the area of FRP shear strengthening in the direction parallel to the shear force, pf is the center-to-center spacing of FRP reinforcement measured orthogonally to the direction of the shear force, $\mathrm{f}_{\mathrm{fd}}$ is the design strength of FRP reinforcement, defined as the lesser between FRP tensile failure strength and debonding strength and $t$ is the thickness of the masonry panel.

The maximum value $\mathrm{V}_{\mathrm{Rd} \text {,max }}$ inducing failure of the compressed strut of the truss mechanism corresponds to:

$$
V_{R d, \max }=0.3 \cdot f_{m d, h} \cdot d \cdot t
$$

where $f_{m d, h}$ is the design compressive strength of the masonry parallel to the mortar joints. It should be noted that the equations above are only valid for FRP strengthening placed parallel to the mortar joints, i.e. grid layout of FRP strips.

In the conducted numerical simulation, the strengthening of masonry piers with carbon FRP (CFRP) strips has been considered. It has been considered in the study that the FRP strips have been installed on both sides of the panels and have been arranged in a grid pattern consisting of two vertical FRP strips at the edges of the pier and three horizontal FRP strips. It has been assumed that the vertical FRP strips run continuously from the bottom to the top storey (Fig. 3a).

The selection of FRP stripes was based on the effective axial stiffness, defined as the product Ef. $\rho_{\mathrm{H}}$, which represents a measure of the effective axial stiffness of the external FRP reinforcement of a masonry panel, where $E_{f}$ is the Young's modulus of FRP and $\rho_{\mathrm{H}}$ is the horizontal FRP reinforcement ratio, defined as the area of horizontal FRP strips on both sides of the panel divided by the product of the height and the thickness of the panel. Based on experimental results by Marcari and co-autohrs [10], the effective axial stiffness equal to $60 \mathrm{MPa}$ has been considered. The authors have concluded that effective axial stiffness of the FRP strips larger than $15 \mathrm{MPa}$ changes the original failure mode of the panels clearly changed from shear to a shear/flexural mode; consequently, larger gains in lateral strength were
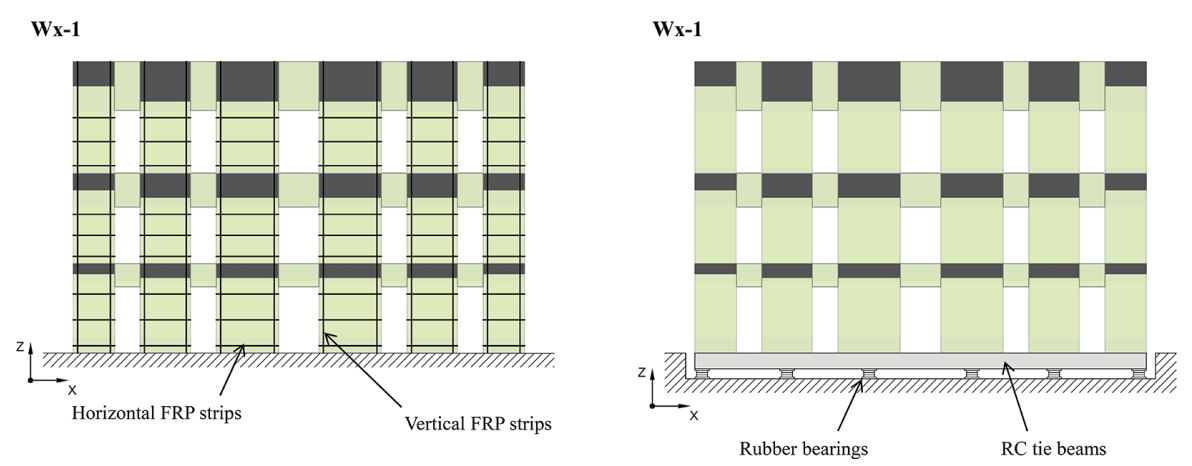

Figure 3: FRP strengthened variant (a) and BI variant (b). 
achieved. Based on this assumption, CFRP strips with the width/thickness ratio $120 \mathrm{~mm} / 1.4$ $\mathrm{mm}$ have been selected $\left(\mathrm{Ef}=21000 \mathrm{kN} / \mathrm{cm} 2, \mathrm{e}_{\mathrm{f}}=0.014\right)$.

The selected FRP characteristics have been included in the mathematical model of the initial, unstrengthened variant by using the same methodology as described in Section 2.2.

\subsection{Base isolation}

The results of base isolation (BI) variants have been added in the paper only for the sake of comparison. The analysis methods and models for BI variants of this building have already been presented by the authors extensively elsewhere $[2,3]$ and are therefore not repeated in this paper.

\section{ASSESSMENT OF SEISMIC PERFORMANCE}

\subsection{Eurocode 8 requirements}

Part 3 of Eurocode 8, i.e. EC8-3 [11], which deals with the assessment and retrofitting of existing buildings, is based on recent trends regarding performance requirements and checks of compliance in terms of displacements, providing also a degree of flexibility to cover the large variety of situations arising in practice. The fundamental requirements of EC8-3 refer to the state of damage in the structure that is defined by means of three limit states presented in Table 2.

In order to achieve an appropriate level of protection, EC8-3 takes into account a different seismic return period for each of the limit states. Longer return periods are associated with greater seismic intensities. Although it should be pointed out, that many heritage buildings have resisted earthquakes with limited damage only, even when their calculated resistance has not completely met code requirements.

This allows for the code-based ground acceleration values that are in use in new buildings to be reduced, meaning that a higher probability of exceedance is admitted. In turn, the considered return periods vary from country to country and are given in the corresponding National Annexes to EC8-3. Table presents the return periods and corresponding peak ground acceleration (PGA) values, referring to the site of the analysed building, which is located on sub-soil class $C$ ( soft site, soil factor $S=1.15$ ). The PGAs indicated in the table refer to a hard site (foundation on rock).

\subsection{Nonlinear static analyses and comparison of results}

The seismic performance was examined for the following variants: (i) the initial unstrengthened structure, i.e. fixed-base (FB) variant, (ii) FRP-Strengthened variant (FRP) and (iii)

Table 2: Performance requirements based on EC8-3, indicating the corresponding return periods and peak ground accelerations of the examined building.

\begin{tabular}{lll}
\hline EC8-3 Limit state & Return period & PGA on rock \\
\hline Damage limitation (DL) & 95 years & $0.15 \mathrm{~g}$ \\
Significant damage (SD) & 475 years & $0.25 \mathrm{~g}$ \\
Near collapse (NC) & 2475 years & $0.43 \mathrm{~g}$ \\
\hline
\end{tabular}


Base-Isolated variant (BI). Since it was concluded in the previous study [3] that the X-direction seismic response is more critical than that in the Y-direction, in this paper only the seismic performance for the loading in $\mathrm{X}$-direction of the building was analysed.

\subsubsection{Capacity curve comparison}

A nonlinear static (pushover) analysis was conducted. The demand parameter that was compared to the capacity was the top (roof) displacement. The N2 method [12] was used to determine the demand top displacement by comparing the intersection between the capacity obtained by pushover analysis and by an inelastic response spectrum. A lateral load pattern proportional to the first mode of vibration was considered. Lateral loads (weighted, taking into account the nodal masses) were applied to the nodes corresponding to the individual storey levels.

Pushover curves of analysed variants, indicating the base shear vs. the lateral roof (top) displacement relationship, are presented in Fig. 4. The protection levels which are defined in EC8-3 as the limit states DL, SD and NC are also indicated in the figure. It can be seen that the capacities of the FB and BI variants are directly comparable. It should be noted that in order to assess the effects of BI on the initial structure, the relative displacements need to be observed and compared. The relative displacements indicate the lateral top displacement with respect to the $\mathrm{BI}$ level, i.e. subtracting the lateral displacements due to the base isolation. In the

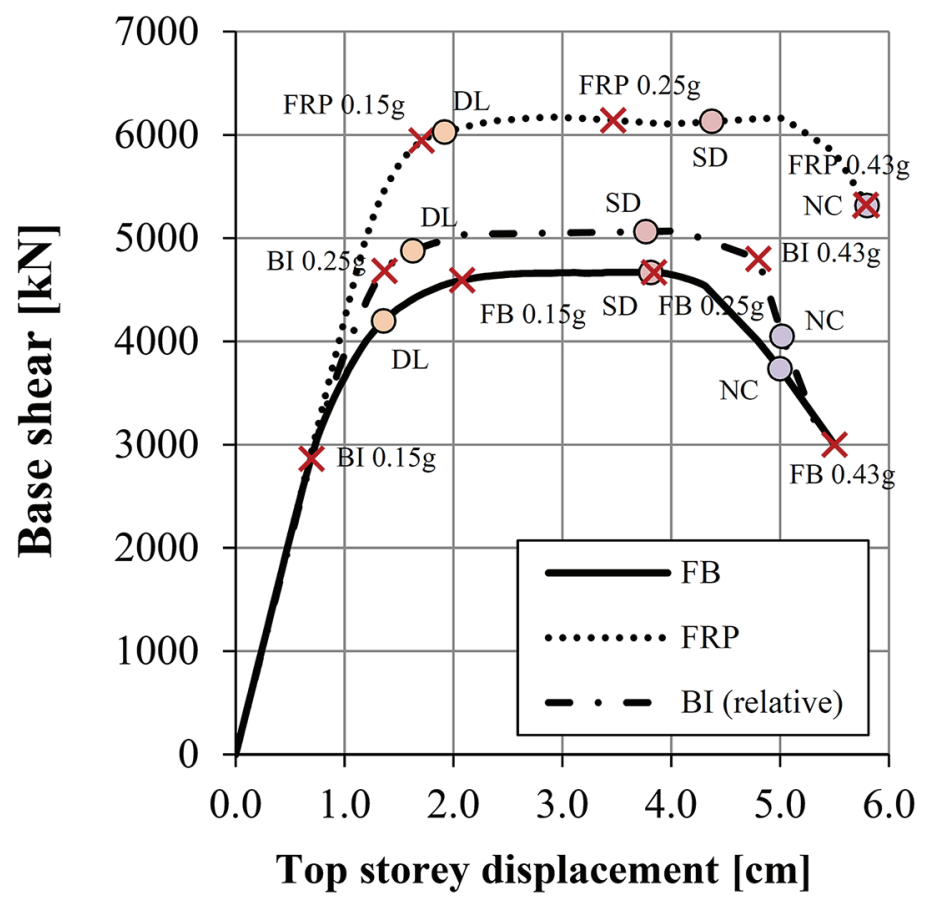

- Seismic capacity (Limit states: DL, SD and NC)
$\times \quad$ Seismic demand (PGA: $0.15 \mathrm{~g}, 0.25 \mathrm{~g}$ and $0.43 \mathrm{~g}$ )

Figure 4: Comparison of pushover curves. 
BI case, the maximum base shear is slightly larger due to the different lateral force distribution, and due the difference in the total seismic mass of the FB and BI variants. The FRP variant, on the other hand, can withstand an approximately 30\% larger maximum base shear force when compared to the initial FB variant.

\subsubsection{Seismic demand displacements and damage patterns}

The seismic demand displacements were calculated by employing the N2 method for PGA levels corresponding to the observed limit states DL, SD and NC (Table 2). It can be seen from Fig. 5 that the FB structure exhibits inadequate seismic performance for all three observed limit states, i.e. the corresponding demand exceeds the capacity requirements.

In the case of the FRP and BI variants for the PGA $=0.15 \mathrm{~g}$ and $0.25 \mathrm{~g}$ (the DL and SD limit states, respectively), the structure's top displacement is smaller than the displacement of the observed limit state. This means that in both cases, the structure has been adequately strengthened for the analysed limit state. Moreover, the displacement of the BI variant is for both PGAs smaller than the DL limit state, indicating limited and repairable damage to the structure also in the case of PGA $=0.25 \mathrm{~g}$.

When observing the demand displacement for PGA $=0.43 \mathrm{~g}$, the structure's performance is inadequate for all three examined variants. In the case of the FB and also FRP strengthened variants, the structure would for this PGA value reach its maximum displacement, indicating its collapse. The BI variant would, based on the results, be heavily damaged and would be very close to collapsing.

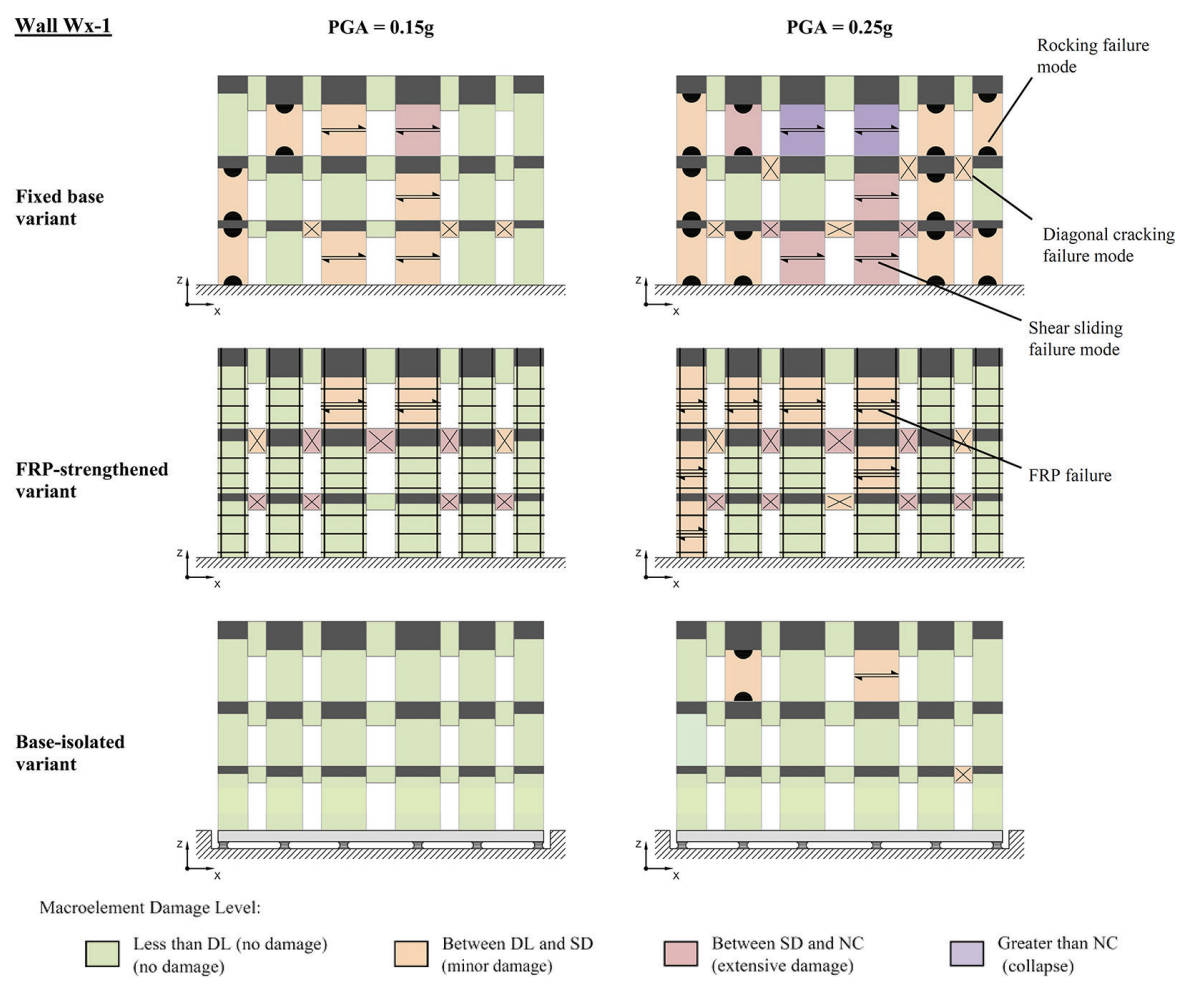

Figure 5: Damage patterns of analysed variants. 


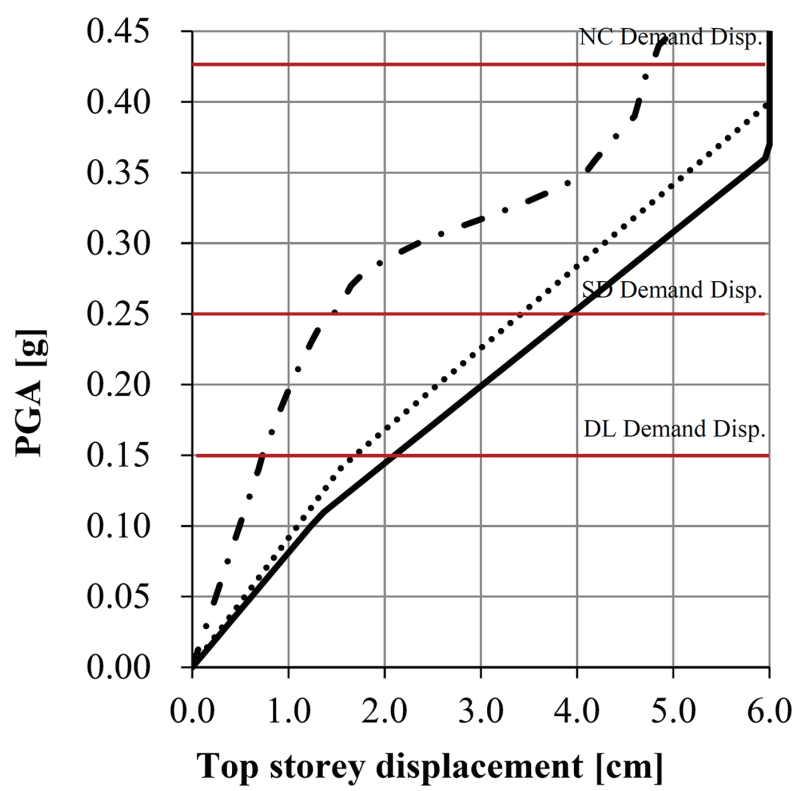

Figure 6: Comparison of IN2 curves.

For PGA $=0.15 \mathrm{~g}$ and $0.25 \mathrm{~g}$, the damage patterns of the structure for all three variants are presented in Fig. 6 for the wall Wx-1. The type of failure mechanism and the level of damage are indicated for each macroelement. The specific macroelement limit chord rotations are given in Table 1. It can be seen from Fig. 6 that the FB variant is heavily damaged in the case of PGA $=0.25 \mathrm{~g}$. The piers of the top storey are all damaged, some of them considerably. A similar observation can be made for the piers and spandrels in the base storey. All the damage grades which are higher than the SD macroelement limit state indicate damage that is very difficult and uneconomic to repair.

The FRP strengthened variant receives significantly less damage in the case of PGA = $0.25 \mathrm{~g}$. The damage mostly concentrated in the top storey, where the axials forces in the pier are smaller. It should also be noted that since the strengthening of spandrels was not considered, most of the spandrels in the model are heavily damaged.

The least amount of damage was recorded in the case of the BI variant. For the target PGA $=0.25 \mathrm{~g}$, it can be seen that the structure undergoes minor damage, which is likely to be repairable. Damage is localised in two piers in the top storey. This is consistent with the EC8-3 requirements for the DL limit state, which allows the occurrence of local damage, where repair measures are usually not needed or are very limited.

\subsubsection{Top storey displacements for varying PGA levels}

In the final part, the relationship between the top storey displacements and the PGA was analysed by progressively increasing the PGA in a stepwise fashion. In each step, the seismic demand displacement has been calculated by using the N2 method. Such an analysis, which has been given the name 'incremental N2 analysis' (IN2), was first introduced and applied to infilled RC frames [13]. In the conducted IN2 analyses, forty-five consecutive intensity levels were considered, ranging from $\mathrm{PGA}=0.01 \mathrm{~g}$ to $\mathrm{PGA}=0.45 \mathrm{~g}$, with a $0.01 \mathrm{~g}$ step size. 
The results of the analyses are presented in Fig. 6. It can be seen from the figure that the IN2 curves for the FB and FRP variants follow the same trend and that in the PGA range from approximately $0.15 \mathrm{~g}$ to $0.37 \mathrm{~g}$ the FRP variant yields about $15 \%$ smaller seismic demand displacements, leading to reduced damage in the piers and different damage pattern distributions. In the case of the BI variant, this difference is more profound. It is largest at PGA $=0.20 \mathrm{~g}$ where the seismic demand displacement of the $\mathrm{BI}$ variant equals to $34 \%$ of that of the FB variant.

\section{CONCLUSIONS}

Two seismic strengthening measures of an existing unreinforced masonry structure have been considered. In the first variant, FRP composites have been used, whereas in the second variant seismic $\mathrm{BI}$ has been implemented. It has been shown that the BI variant of the building obtains significantly less seismically induced damage than the FRP variant. It was concluded that both strengthening measures provide sufficient lateral strength increases to meet basic code requirements.

It is, however, not easy to implement the base isolated system under the existing building. Such endeavour is possible, but seldom financially feasible and reserved only to buildings that meet specific requirements of value and importance. The presented results for base isolated building are to be seen more as a presentation of maximum earthquake resistance capacity, which could be achieved for the structure without additional invasive retrofitting measures. It usually depends on the conservation plan set up by conservator, architect and structural engineer that determines the measures suitable for particular building. The strengthening with FRP is usually appropriate for most buildings, since it can be applied on inner/ outer or on bout sided of existing walls.

The presented microelement modelling technique for URM structures developed by the authors enables also a comparison of effectiveness of different seismic retrofitting techniques and selection of the most suitable for particular building and location, which was demonstrated on two selected retrofitting techniques applied in this paper.

\section{ACKNOWLEDGEMENTS}

The results presented in this article are based on work that was supported by the Slovenian Research Agency (grant number P5-0068). The authors greatly acknowledge the financial support for this research.

\section{REFERENCES}

[1] Prota, A., Manfredi, G. \& Nardone, F., Assessment of design formulas for in-plane FRP strengthening of masonry walls. Journal of Composites for Construction, 12(6), pp. 643-649, 2008. https://doi.org/10.1061/(asce)1090-0268(2008)12:6(643)

[2] Kelly, J.M., Robinson, B.W.H. \& Skinner, R.I., Seismic Isolation for Designers and Structural Engineers, Robinson Seismic Limited, New Zealand, 2007.

[3] Petrovčič, S. \& Kilar, V., Seismic failure mode interaction for the equivalent frame modeling of unreinforced masonry structures. Engineering Structures, 30(54), pp. 9-22, 2013. https://doi.org/10.1016/j.engstruct.2013.03.050

[4] Petrovčič, S. \& Kilar, V., Seismic retrofitting of historic masonry structures with the use of base isolation-modeling and analysis aspects. International Journal of Architectural Heritage, 11(2), pp. 229-246, 2016. https://doi.org/10.1080/15583058.2016.1190881 
[5] Parisi, F. \& Augenti, N., Seismic capacity of irregular unreinforced masonry walls with openings. Earthquake Engineering \& Structural Dynamics, 42(1), pp. 101-121, 2013. https://doi.org/10.1002/eqe.2195

[6] Kappos, A.J. \& Papanikolaou, V.K., Nonlinear dynamic analysis of masonry buildings and definition of seismic damage states. The Open Construction and Building Technology Journal, 10(1), pp. 192-209, 2016. https://doi.org/10.2174/1874836801610010192

[7] Magenes, G. \& Calvi, G.M., In-plane seismic response of brick masonry walls. Earthquake Engineering \& Structural Dynamics, 26(11), pp. 1091-1112, 1997. https://doi.org/10.1002/(sici)1096-9845(199711)26:11<1091::aid-eqe693>3.3.co;2-y

[8] CSI - Computers and Structures, SAP2000 Ultimate (v18.2.0) - Structural Analysis Program. Berkeley, USA, 2016.

[9] CNR - Advisory Committee on Technical Recommendations for Construction, Guide for the Design and Construction of Externally Bonded FRP Systems for Strengthening Existing Structures. CNR, Rome, 2016.

[10] Marcari, G., Manfredi, G., Prota, A. \& Pecce, M., In-plane shear performance of masonry panels strengthened with FRP. Composites Part B: Engineering, 38(7), pp. 887-901, 2007. https://doi.org/10.1016/j.compositesb.2006.11.004

[11] CEN - European Committee for Standardisation, Eurocode 8: Design of structures for earthquake resistance - Part 3: General rules, seismic actions and rules for buildings, Design Code EN 1998-3. CEN, Brussels, 2005.

[12] Fajfar, P., A nonlinear analysis method for performance-based seismic design. Earthquake Spectra, 16(3), pp. 573-592, 2000. https://doi.org/10.1193/1.1586128

[13] Dolšek, M. \& Fajfar, P., Simplified non-linear seismic analysis of infilled reinforced concrete frames. Earthquake Engineering \& Structural Dynamics, 34, pp. 49-66, 2005. https://doi.org/10.1002/eqe.411 